\title{
ОБ ОДНОМ ИЗ СПОСОБОВ КЛАССИФИЦИРОВАНИЯ УРОВЕННОГО РЕЖИМА ПОДЗЕМНЫХ ВОД ЭСТОНИИ
}

В тех случаях, когда требуется определить уровенный режим подземных вод, а гидростратиграфическая картина разреза недостаточно ясна, возникает вопрос - какими рядами наблюдения следует охарактеризовать тот или иной водоносный горизонт?

Основными источниками информации о гидростратиграфии разреза являются описания пород, пройденных буровой скважиной, и результаты исследований, проведенных в ней. Однако часть пространства, характеризуемая буровой скважиной, или даже кустом скважин, несонзмерима с размерами водоносного горизонта. С увеличением числа скважин растет несопоставимость получаемых данных. Устанавливаются только некоторые статистические закономерности, например, уменьшение с глубиной коэффициента фильтрации (в карбонатных породах).

В то же время известно, что наблюдения за уровенным режимом в одиночной скважине могут дать информацию о значительной части водоносного горизонта. Следовательно, анализ уровенного режима подземных вод представляет большую ценность для уточнения гидростратиграфии разреза пород.

Некоторые наблюдательные скважины вскрывают несколько водоносных горизонтов. В таких скважинах формируется смешанный режим, параметры которого зависят от режима и водопроводимостей соседних горизонтов. Радиусы влияния самой скважины на режим этих горизонтов определяются разницей напоров в них. Обычно эта разница небольшая и поэтому оказываемое скважиной влияние не может быть существенным. Обратное же влияние весьма значительно. Например, при равных водопроводимостях колебания уровней в скважине равняются среднеарифметическому от колебаний уровней связанных горизонтов. Такой же смешанный режим формируется и в естественных условиях, в местах, где водоносные горизонты имеют гидравлическую связь.

Чтобы установить факт смешения режима и его характер (естественный или возникший в наблюдательной скважине), а также параметры режима отдельных водоносных горизонтов, проведем классифицирование хронологических графиков уровенного режима подземных вод.

\section{Методика классифицирования}

Классифицированием хронологических графиков можно установить режим двух водоносных горизонтов, если: 1) часть наблюдательных скважин вскрывает только один водоносный горизонт, 2) режим двух 
водоносных горизонтов различен, 3) различия между режимом отдельных участков водоносного горизонта (между разновидностями режима) меньше, чем различия между режимом отдельных водоносных горизонтов (между видами режима).

Если эти требования выполняются, тогда хронологические графики можно сгруппировать таким образом, чтобы каждой группе соответствовал некоторый вид режима. Наиболее объемистые группы будем считать фоновыми, предполагая, что вероятность попадания на фон больше вероятности попадания на локальные виды режима.

Поскольку в общем случае число видов режима не известно, воспользуемся иерархическим агломеративным методом классифицирования (Крамбейн и др., 1973). Для этого выберем некоторую меру сходства между графиками режима.

Мерой сходства может быть положительное число, характеризующее по выбранным признакам сходство двух объектов. В качестве признаков возьмем среднемесячные уровни подземных вод, приведенные центрированием к единому началу отсчета:

$$
H_{i k}^{*}=H_{i k}-\bar{H}_{i} \text {, }
$$

где $H_{i k}-$ средний уровень в $k$-м месяце на $i$-м объекте, $\bar{H}_{i}-$ среднегодовой уровень и $H_{i k}^{*}$ - центрированный среднемесячный уровень. Представим центрированные среднемесячные уровни как прямоугольные координаты объекта в $n$-мерном пространстве. Тогда мерой сходства объектов $i$ и $j$ может быть расстояние между ними в этом пространстве

$$
d_{i j}=\sqrt{\sum_{k=1}^{n}\left(H_{i k}^{*}-H_{j k}^{*}\right)^{2}}
$$

Расстояние (2) учитывает в основном годовые амплитуды колебаний уровней, на фоне которых сезонные колебания выпадают из виду. Если же за меру сходства принять коэффициент корреляции, который учитывает синхронность колебаний уровней, тогда выпадут из виду амплитуды колебаний уровней. Чтобы сделать учет коррелятивных зависимостей наиболее полным, придадим ежемесячным уровням одинаковый вес путем нормирования координат (центрированных среднемесячных уровней). Для этого разделим каждую координату на разность ее максимального и минимального значений по всем $N$ объектам. Вместо исходных рядов среднемесячных уровней будем рассматривать их центрированные и нормированные значения

$$
X_{i k}=\frac{H_{i k}^{*}}{\max H_{(1,2, \ldots, N) k}^{*}-\min H_{(1,2, \ldots, N) k}^{*}} .
$$

Мера сходства, т. е. расстоянне между объектами, вычисляется аналогично формуле (2):

$$
d_{i j}^{*}=\sqrt{\sum_{k=1}^{n}\left(X_{i k}-X_{j k}\right)^{2}}
$$

Меняясь от нуля до корня квадратного от числа координат, данная мера сходства отвечает требованию положительности.

При сравнении выборки синусоид, имеющих одинаковые частоты, но 
различные амплитуды, видно, что мера сходства (4) имеет максимальное значение при синусоидах с экстремальными амплитудами. Коэффициенты корреляции этой же выборки все равны плюс единице, т. е. синусоиды неразличимы. В тех случаях, когда некоторые синусоиды в выборке находятся в противоположных фазах, коэффициент корреляции меняется в интервале от минус единицы до плюс единицы, а мера сходства (4) остается положительной. Хотя при естественном режиме подземных вод появление отрицательных коррелятивных связей в течение всего года маловероятно, использовать коэффициенты корреляции в качестве меры сходства не имеет смысла. Ведь смещение фаз проявляется в среднемесячных уровнях слабо, и по признаку синхронности колебаний уровней все водоносные горизонты окажутся неразличимыми.

Изложим порядок классифицирования. Сначала вычисляются все возможные $\left(\begin{array}{l}N \\ 2\end{array}\right)$ расстояния между объектами по формуле (4). Затем приступают к попарному объединению групп и повторяют эту процедуру до тех пор, пока все объекты не окажутся в определенном иерархическом порядке в одной группе (в начале процедуры каждый объект представляет собой самостоятельную группу). На каждом шагу классифицирования объединяются две группы так, чтобы у вновь образовавшейся группы среднее внутригрупповое расстояние было наименьшим. Для этого просматриваются все возможности попарного объединения групп. На первом шагу перебираются $\left(\begin{array}{l}N \\ 2\end{array}\right)$ сочетания, на втором $\left(\begin{array}{c}N-1 \\ 2\end{array}\right)$ и т. д. Среднее внутригрупповое расстояние определяется как среднеарифметическое от расстояний (4) между объектами данной группы. Например, если расстояния между объектами $M_{1}, M_{2}$ и $M_{3}$ обозначить через $d_{12}^{*}$, $d_{13}^{*}$ и $d_{23}^{*}$, то искомое будет равно $\left(d_{12}^{*}+d_{13}^{*}+d_{23}^{*}\right): 3$. Среднее внутригрупповое расстояние в группе, состоящей из двух объектов, равно мере сходства (4).

Итак, на первом шагу классифицирования образуется группа из двух наиболее сходных объектов, на втором шагу $\mathrm{k}$ ней либо добавляется третий объект, либо образуется еще одна группа из двух объектов и т. д.

Результаты классифицирования могут быть представлены в виде дендрографа. Построенный исходя из меры сходства (4) дендрограф позволяет судить лишь о сходстве объектов, а не о степени их различия. Большие расстояния между объектами указывают только на то, что попавшие в некоторую конкретную выборку объекты наименее сходны. Следовательно, если руководствоваться выборкой слабо различающихся объектов, можно придти к ошибочным выводам, приняв ее за выборку сильно различающихся объектов. Поэтому при интерпретации дендрографа следует следить за тем, чтобы выделенные группы имели гидрогеологическое обоснование.

\section{Результаты классифицирования}

В целях опробования описанного метода классифицирования были проанализированы данные режимных наблюдений гидрогеологических постов Управления геологии СМ ӘССР и Гидрометслужбы ЭССР. Для вычислений была использована программа, разработанная в Институте кибернетики АН ЭССР.

Из всех расположенных в районе Северо-Әстонского водораздела наблюдательных точек были выбраны 37 , где проводились ежемесячные 


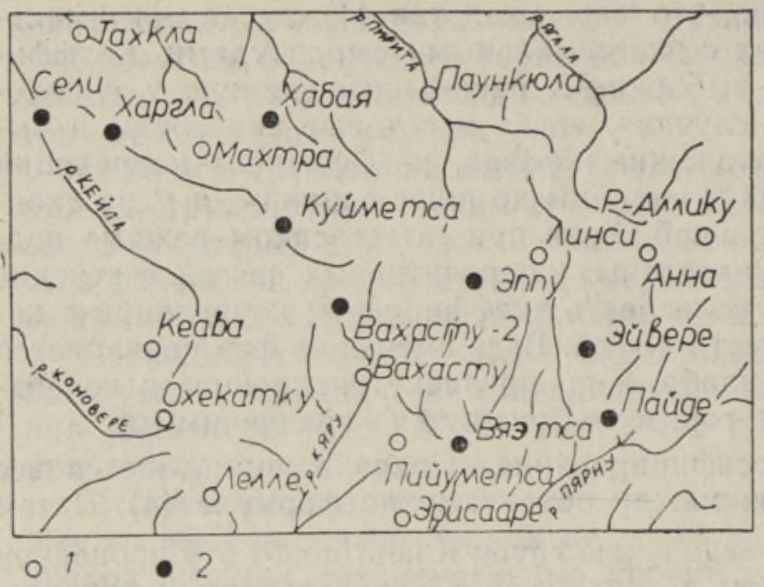

Рис. 1. Расположение точек наблюдения: 1 - наблюдательная скважина, 2 - группа наблюдательных скважин.

непрерывные наблюдения начиная с ноября 1970 года. В выборку включили посты Ао, Люганузе и Мыдусааре, поскольку режим их грунтовых вод предполагался различным из-за большой удаленности от исследуемого района, площадь которого составляет около $400 \kappa \mathrm{M}^{2}$ (рис. 1).

В табл. 1 порядок расположения объектов соответствует результатам классифицирования, определенным исходя из меры сходства (4). Графическое изображение классифицирования показано на дендрографе (рис. 2).

Дендрографы, построенные исходя из меры сходства (2), а также исходя из коэффициента корреляции, по указанным выше причинам не дали хороших результатов. Была опробована еще одна мера сходства как частное от деления коэффициента корреляции на меру сходства (4). Полученный в результате дендрограф не позволил связать образовавшиеся группы с определенными водоносными горизонтами, хотя графики режима оказались упорядоченными по внешним признакам лучше, чем исходя только из меры сходства (4). По-видимому, сравнивая особенности режима подземных вод, не следует придавать синхронности колебаний уровней слишком большого значения.

Нормированием по формуле (3) уменьшали величины центрированных среднемесячных уровней соответственно их изменчивости по месяцам (табл. 2). Смысл этой процедуры состоит в том, чтобы при сравнении режима подземных вод придать зимним уровням такой же вес, как и летним. В нашем примере мы присвоили ноябрьскому уровню в 2,25 раза бо́льшее значение, чем апрельскому. Отсюда становится ясно, почему в выделенных группах режима годовые амплитуды колебаний

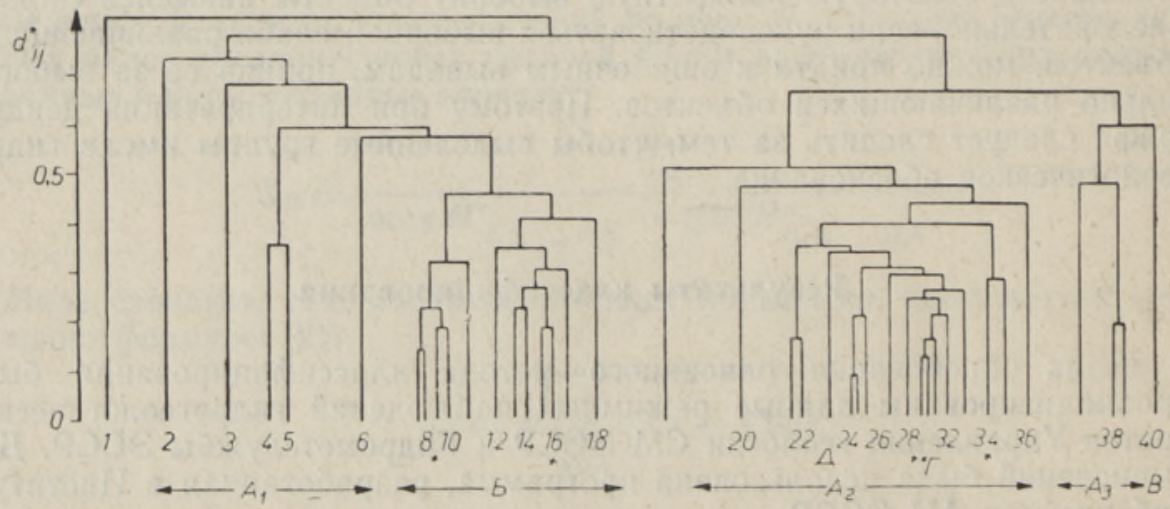

Рис. 2. Дендрограф: $A_{1}, A_{2}, A_{3}$, Б, В, Г, Д-группы объектов, * - объекты группы $\mathrm{A}_{2} \mathrm{~B}$. 
Характеристика точек наблюдения и уровенного режима подземных вод

\begin{tabular}{|c|c|c|c|c|c|c|c|c|}
\hline & Наблюда & ельная скваж & & & Уровенн & ый режим & & \\
\hline & & Вскрытый & интервал & $\begin{array}{l}\text { Средне- } \\
\text { год. уро- }\end{array}$ & & Диспер- & & \\
\hline 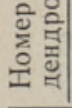 & пол & $\begin{array}{l}\text { Геол. } \\
\text { индекс }\end{array}$ & $\underset{\mu}{\text { Глубина, }}$ & $\begin{array}{c}\text { от по- } \\
\text { верх. } \\
\text { земли }\end{array}$ & $\begin{array}{l}\text { ампли- } \\
\text { туда, } \mu\end{array}$ & $\begin{array}{c}\text { немес. } \\
\text { уровней }\end{array}$ & $\begin{array}{l}\text { ходом } \\
\text { р. Кейла }\end{array}$ & 氖 \\
\hline $\begin{array}{l}1 \\
2 \\
3 \\
4 \\
5 \\
6\end{array}$ & $\begin{array}{l}\text { Мыдусааре } \\
\text { Эйвере } \\
\text { Райгу } \\
\text { Райгу } \\
\text { Сели } \\
\text { Харгла }\end{array}$ & $\begin{array}{l}\mathrm{Q}_{3} \\
\mathrm{glQ}_{3} \\
\mathrm{~S}_{1 \mathrm{jr}}-\mathrm{O}_{2} \mathrm{kl} \\
\mathrm{S}_{1 \mathrm{jr}} \\
\mathrm{glQ}_{3} \\
\mathrm{O}_{3} \mathrm{pk}\end{array}$ & $\begin{array}{c}0-6 \\
0-4 \\
17-211 \\
3-7 \\
0-9\end{array}$ & $\begin{array}{l}2,02 \\
1,46 \\
2,02 \\
1,88 \\
0,85 \\
6,13\end{array}$ & $\begin{array}{r}3,01 \\
2,52 \\
2,92 \\
1,97 \\
1,22 \\
2,73 \\
\text { Cp. } 2,40\end{array}$ & $\begin{array}{r}1,29 \\
1,02 \\
0,88 \\
0,59 \\
0,40 \\
0,77 \\
\text { Cp. } 0,83\end{array}$ & $\begin{array}{r}0,97 \\
0,76 \\
0,90 \\
0,76 \\
0,83 \\
0,97 \\
\text { Cp. } 0,87\end{array}$ & $A_{1}$ \\
\hline $\begin{array}{r}7 \\
8 \\
10 \\
11 \\
12 \\
13 \\
14 \\
15 \\
17 \\
18\end{array}$ & $\begin{array}{l}\text { Кеава } \\
\text { Хабая } \\
\text { Пийуметса } \\
\text { Анна } \\
\text { Сели } \\
\text { Махтра } \\
\text { Пайде } \\
\text { Лелле } \\
\text { Куйметса } \\
\text { Паункюла }\end{array}$ & $\begin{array}{l}\mathrm{O}_{3} \mathrm{pk}-\mathrm{O}_{1} \mathrm{pk} \\
\mathrm{O}_{2} \mathrm{On}-\mathrm{O}_{1} \mathrm{pk} \\
\mathrm{S}_{1} \mathrm{jr}-\mathrm{O}_{1} \mathrm{vl} \\
\mathrm{O}_{3} \mathrm{pg}-\mathrm{O}_{2} \mathrm{kk} \\
\mathrm{lgl}_{3} \\
\mathrm{O}_{3} \mathrm{pg}-\mathrm{O}_{2} \mathrm{on} \\
\mathrm{O}_{3} \mathrm{pk}-\mathrm{O}_{1} \mathrm{pk} \\
\mathrm{S}_{1} \mathrm{jr}-\mathrm{O}_{1} \\
\mathrm{O}_{3} \mathrm{pk}-\mathrm{O}_{2} \mathrm{kl} \\
\mathrm{O}_{3}\end{array}$ & $\begin{array}{c}58-236 \\
86-148 \\
75-242 \\
4-177 \\
3-6 \\
7-107 \\
50-289 \\
23-128\end{array}$ & $\begin{array}{l}9,66 \\
5,71 \\
1,38 \\
0,60 \\
3,04 \\
1,40 \\
1,29 \\
1,81 \\
2,32 \\
2,52\end{array}$ & $\begin{array}{r}1,33 \\
1,02 \\
1,42 \\
1,74 \\
2,33 \\
1,70 \\
1,84 \\
1,61 \\
2,12 \\
1,67- \\
\text { Cp. } 1,68\end{array}$ & $\begin{array}{r}0,48 \\
0,40 \\
0,53 \\
0,64 \\
0,75 \\
0,62 \\
0,67 \\
0,60 \\
0,70 \\
0,58 \\
\text { Cp. } 0,60\end{array}$ & $\begin{array}{r}0,85 \\
0,82 \\
0,80 \\
0,82 \\
0,92 \\
0,74 \\
0,77 \\
0,79 \\
0,79 \\
0,74 \\
0,74 \\
\text { Cp. } 0,80\end{array}$ & Б \\
\hline $\begin{array}{r}9 \\
16 \\
29 \\
30 \\
34\end{array}$ & $\begin{array}{l}\text { Эйвере } \\
\text { Куйметса } \\
\text { Линси } \\
\text { Тахкла } \\
\text { Вахасту }\end{array}$ & $\begin{array}{l}\mathrm{S}_{1} \mathrm{rk}-\mathrm{jr} \\
\mathrm{S}_{1} \mathrm{jr} \\
\mathrm{S}_{1} \mathrm{jr}-\mathrm{O}_{3} \mathrm{vr} \\
\mathrm{S}_{1} \mathrm{rk}-\mathrm{O}_{2} \mathrm{kl} \\
\mathrm{S}_{1} \mathrm{rk}-\mathrm{O}_{3} \mathrm{pk}\end{array}$ & $\begin{array}{r}7-26 \\
2-13 \\
11-89 \\
6-79 \\
7-58\end{array}$ & $\begin{array}{l}3,05 \\
1,71 \\
0,12 \\
1.29 \\
0,54\end{array}$ & $\begin{array}{r}1,28 \\
1,84 \\
0,89 \\
1,07 \\
1,45 \\
\text { Cp. } 1,31\end{array}$ & $\begin{array}{r}0,44 \\
0,67 \\
0,32 \\
0,36 \\
0,56 \\
\text { Cp. } 0,47\end{array}$ & $\begin{array}{r}0,84 \\
0,79 \\
0,84 \\
0,84 \\
0,75 \\
\text { Cp. } 0,81\end{array}$ & $\mathrm{~A}_{2} \mathrm{~B}$ \\
\hline $\begin{array}{l}19 \\
20 \\
21 \\
22 \\
24 \\
25 \\
26 \\
27 \\
28 \\
32 \\
33 \\
35 \\
36\end{array}$ & $\begin{array}{l}\text { Р-Аллику } \\
\text { Люганузе } \\
\text { Сели } \\
\text { Ао } \\
\text { Вахасту-2 } \\
\text { Вахасту-2 } \\
\text { Эппу } \\
\text { Хабая } \\
\text { Охекатку } \\
\text { Вяэтса } \\
\text { Пайде } \\
\text { Вяэтса } \\
\text { Эрисааре }\end{array}$ & 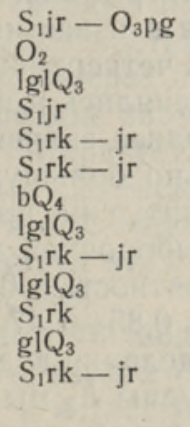 & $\begin{array}{c}8-62 \\
0-8 \\
4-6 \\
0-5 \\
5-38 \\
0-4 \\
0-6 \\
2-6 \\
13-70 \\
2-5 \\
5-34 \\
0-3 \\
8-85\end{array}$ & $\begin{array}{l}0,14 \\
1,69 \\
0,40 \\
2,39 \\
0,18 \\
0,32 \\
1,59 \\
1,01 \\
1,30 \\
0,52 \\
1,01 \\
1,49 \\
0,73\end{array}$ & $\begin{array}{r}0,49 \\
1,85 \\
0,88 \\
1,03 \\
0,71 \\
0,80 \\
0,68 \\
1,09 \\
1,02 \\
1,12 \\
1,37 \\
1,85 \\
2,17 \\
\text { Cp. } 1,16\end{array}$ & $\begin{array}{r}0,18 \\
0,60 \\
0,26 \\
0,30 \\
0,25 \\
0,27 \\
0,22 \\
0,36 \\
0,36 \\
0,42 \\
0,45 \\
0,65 \\
0,87 \\
\text { Cp. } 0,40\end{array}$ & $\begin{array}{r}0,78 \\
0,60 \\
0,94 \\
0,91 \\
0,80 \\
0,55 \\
0,79 \\
0,78 \\
0,96 \\
0,81 \\
0,86 \\
0,76 \\
0,70 \\
\text { Cp. } 0,79\end{array}$ & $\mathrm{~A}_{2}$ \\
\hline 31 & Харгла & $\mathrm{O}_{3} \mathrm{kl}-\mathrm{O}_{1} \mathrm{It}$ & $112-166$ & 9,65 & 0,79 & 0,34 & 0,72 & $\Gamma$ \\
\hline 23 & Вахасту-2 & $\mathrm{O}_{1} \mathrm{pk}-\in \mathrm{ts}$ & $220-242$ & 16,71 & 0,14 & 0,05 & 0,83 & д \\
\hline $\begin{array}{l}37 \\
38 \\
39\end{array}$ & $\begin{array}{l}\text { Вяэтса } \\
\text { Хабая } \\
\text { Хабая }\end{array}$ & $\begin{array}{l}\mathrm{glQ}_{3} \\
\lg \mid Q_{3}\end{array}$ & $\begin{array}{l}0-3 \\
0-4\end{array}$ & $\begin{array}{l}1,34 \\
1,14 \\
0,93\end{array}$ & $\begin{array}{r}1,95 \\
1,50 \\
1,39 \\
\text { Cp. } 1,61\end{array}$ & $\begin{array}{r}0,83 \\
0,61 \\
0,56 \\
\text { Cp. } 0,67\end{array}$ & $\begin{array}{r}0,75 \\
0,67 \\
0,71 \\
\text { Cp. } 0,71\end{array}$ & $\mathrm{~A}_{3}$ \\
\hline 40 & Эnny & $\mathrm{S}_{1} \mathrm{jr}-\mathrm{O}_{3} \mathrm{nb}$ & $29-133$ & 1,84 & 1,04 & 0,35 & 0,71 & B \\
\hline
\end{tabular}

уровней распределены почти одинаково. Дело в том, что различия определяются не столько годовыми уровнями, сколько уровнями всех месяцев. Годовая амплитуда может скрыть такие, например, различия, как 
Таблица 2

Максимальные и минимальные центрированные среднемесячные уровни

\begin{tabular}{l|c|c|c|c}
\hline \multirow{2}{*}{ Месяц } & \multicolumn{2}{|c|}{ Уровень, см } & \multicolumn{2}{c}{ Разница } \\
\cline { 2 - 5 } & $\begin{array}{c}\text { максималь- } \\
\text { ный }\end{array}$ & $\begin{array}{c}\text { минималь- } \\
\text { ный }\end{array}$ & cм & $\%$ \\
\hline Ноябрь & 58 & -58 & 116 & 100 \\
Декабрь & 130 & -9 & 139 & 120 \\
Январь & 129 & -39 & 168 & 145 \\
Февраль & 133 & -45 & 178 & 153 \\
Март & 115 & -61 & 176 & 152 \\
Апрель & 235 & -26 & 261 & 225 \\
Май & 169 & -44 & 213 & 185 \\
Июнь & 108 & -125 & 233 & 201 \\
Июль & 54 & -167 & 221 & 191 \\
Август & 27 & -176 & 203 & 175 \\
Сентярь & 14 & -176 & 190 & 164 \\
Октябрь & 9 & -174 & 183 & 158
\end{tabular}

колебания уровней во время зимних оттепелей (рис. 3). Запаздывание экстремальных уровней почти на один месяц, причем в различных частях выделенных водоносных горизонтов, говорит об изолированности этих горизонтов. Примечательно, что в результате классифицирования данные графики оказались в разных группах. Это дает некоторое основание полагать, что среднемесячные уровни содержат достаточно информации, чтобы провести классифицирование по данной методике, и что мера сходства (4) позволяет группировать объекты в таком порядке, который имеет смысл.

Пересечением дендрографа на иерархическом уровне 0,5 количество групп сократилось от сорока до десяти.

В группу $A_{2}$ вошли объекты, для которых характерен режим подземных вод, залегающих выше юуруского стратиграфического горизонта. В основном это грунтовые воды, находящиеся в известняках райккюлаского горизонта, а также в перекрывающих их четвертичных отложениях различного генезиса. Годовые амплитуды изменялись в пределах от 0,49 до $2,17 \mu$, среднее значение $1,16 \mu$. Учи-

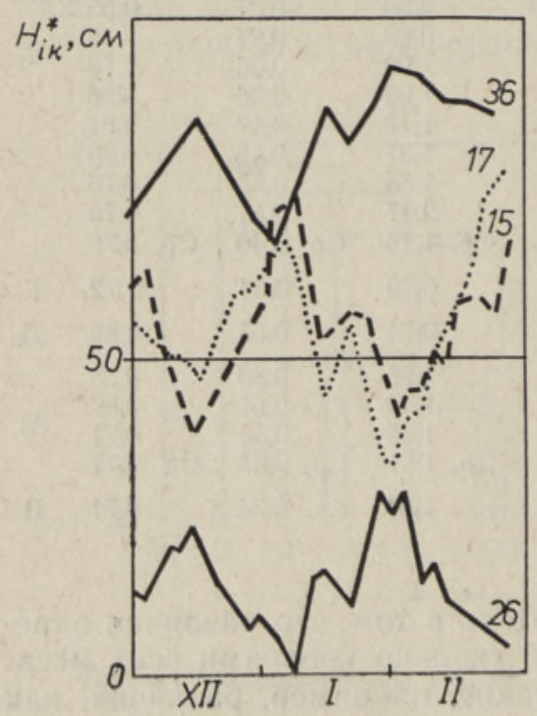
тывая довольно большую изменчивость годовых амплитуд на протяжении всего горизонта (выборочная дисперсия 0,27 ), можно с вероятностью 0,95 утверждать, что интервал $0,85-1,47$ м перекрывает центр распределения годовых амплитуд.

Режим группы $\mathrm{A}_{2}$ мы приняли за фоновый. О его широком распространении свидетельствует сходство режима на исследуемой территории с режимом грунтовых вод в Ао и Люганузе. По-видимому, в неглубоко залегающих карбонатных породах можно почти повсеместно ожидать одинаковых условий формирования уровенного режима подземных вод.

Рис. 3. Колебания уровней подземных вод: 36 и 26 - грунтовые воды, 17 и 15 - напорные воды, 


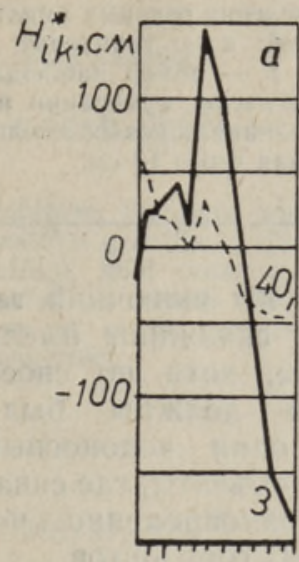

1971

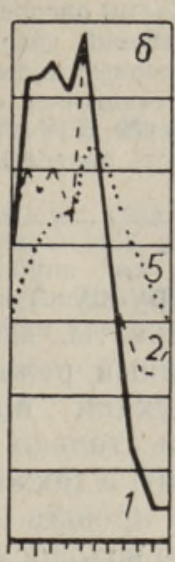

1971

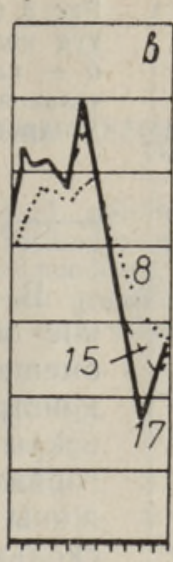

1971

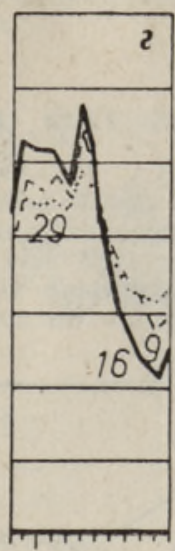

1971

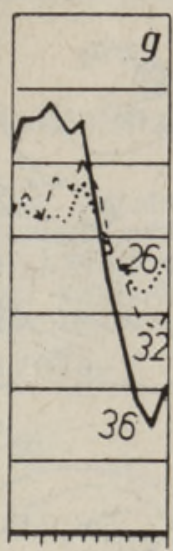

1971

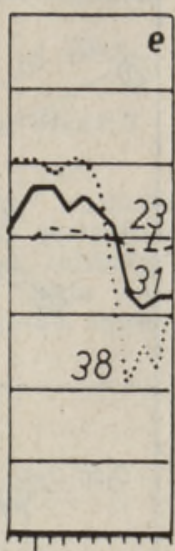

1971

Рис. 4. Кояебания уровней подземных вод: $a-$ наименее сходные графики $(40-$ нарушенный режим); б - группа $A_{1} ; 8$ - группа Б; ट - rруппа $A_{2} Б$; $\partial$ - rруппа $A_{2}$; $\boldsymbol{e}$ - группы $\mathrm{A}_{3}, \Gamma$ и Д (объекты 38,31 и 23 соответственно).

Группы $A_{1}$ и $A_{3}$ содержат несколько разновидностей режима, которые имеют мало сходства как между собой, так и с режимом остальных групп. Объекты этих групп указывают на различные аномалии в режиме подземных вод. Причины их появления можно установить лишь при наличии дополнительной информации о конкретных гидрогеологических условиях на местах:

Вторая большая группа - группа Б - характеризует уровенный режим ордовикских водоносных горизонтов, верхнего и нижнего вместе (Верте, 1965). Амплитуды колебаний уровней находятся в интервале $1,02-2,33 м$, среднее значение $1,68 м$. Центр распределения годовых амплитуд с вероятностью 0,95 перекрывается интервалом $1,37-1,85 \boldsymbol{\mu}$.

Некоторый интерес представляет сравнение годовых амплитуд групп $\mathrm{A}_{2}$ и Б. Их средние значения по выборкам равны 1,16 и 1,68 м соответственно. Нас интересует, можно ли считать это различие случайным или закономерным? Согласно критерию Стьюдента, они различаются существенно с 95\%-ной вероятностью. По критерию же Фишера, дисперсии годовых амплитуд этих групп можно считать различными лишь с $60 \%$ ной вероятностью.

В скв. Эппу наблюдается нарушенный режим верхне-ордовикского водоносного горизонта (группа В), где на фоне пониженных уровней прослеживается и естественный режим (рис. $4, a)$. На том же рисунке изображен ход уровней в Райгу. Мера сходства между этими графиками режима оказалась в данной выборке из сорока объектов максимальной $-2,26$.

Скв. Харгла вскрыла нижне-ордовикский водоносный горизонт (группа Г). Хотя этот объект вошел на дендрографе в группу, которой свойствен режим грунтовых вод, наши данные говорят, что воды нижнеордовикского горизонта не имеют ничего общего с таковым. Последним присущи здесь гораздо большие амплитуды колебаний уровней. Малая годовая амплитуда $(0,79$ м) свидетельствует о том, что с глубиной амплитуды колебаний уровней затухают. Весьма четко это проявляется в скв. Вахасту-2, вскрывшей ордовико-кембрийский водоносный горизонт (группа Д), где годовая амплитуда составляет всего лишь $0,14 \mathrm{M}$. 


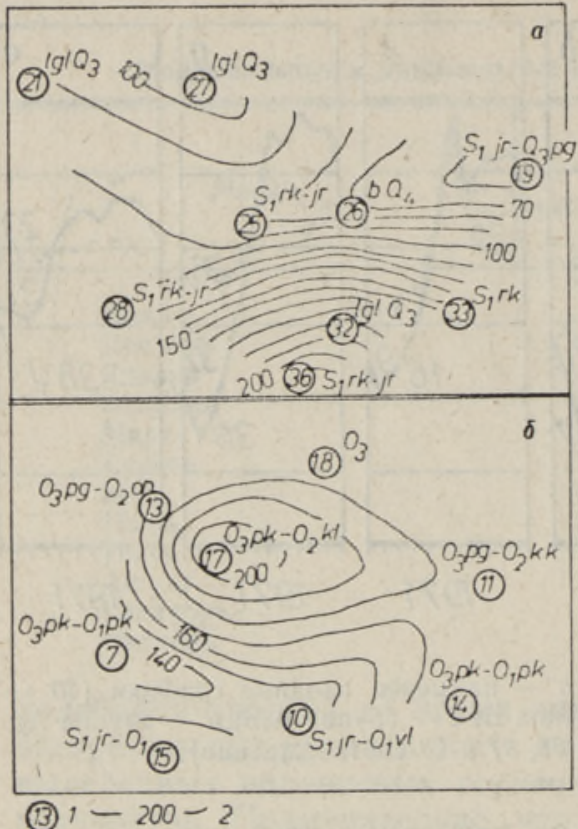

Рнс. 5. Схемы распределения годовых амплитуд колебаний уровней: $a$ - грунтовые н 6 - напорные воды. 1 - номер наблюдательной скважины согласно нумерации на дендрографе, 2 - изолиния годовых амплитуд, проведенная через $10 \mathrm{~cm}$.

В группу $\mathrm{A}_{2} \mathrm{~B}$ мы включили такие объекты, где скважины имели смешанный режим, хотя по своей конструкции они должны были вскрыть только один водоносный горизонт, а также объекты, где скважины прошли одновременно несколько водоносных горизонтов.

Итак, в пределах исследуемой территории можно выделить естественный уровенный режим подземных вод в следующих горизонтах.

1. Горизонт грунтовых вод, залегающий в силурийских и четвертичных отложениях.

2. Ордовикские водоносные горизонты: а) верхне-ордовикский (?), б) нижне-ордовикский.

3. Ордовико-кембрийский горизонт.

В период с ноября 1970 по октябрь 1971 графики режимов в названных горизонтах несколько различались. Из рис. 5 видно, что уровни первого от поверхности земли водоносного горизонта имеют ме́ньшие годовые амплитуды, чем второго, залегающего ниже. В первом горизонте годовые амплитуды увеличиваются в направлении Пийуметса, а во втором - в районе Куйметса.

Для более детального описания уровенного режима данной территории следовало бы привести имеющиеся ряды наблюдения к многолетнему ряду. Предпосылкой для этого служит хорошая коррелируемость режима подземных вод с речным стоком. Весьма интересно было бы выявить, сохраняются ли полученные соотношения параметров режима различных водоносных горизонтов во времени? Если это так, тогда приведение коротких рядов наблюдения к многолетнему ряду не представляет особых трудностей, так как в этом случае можно удлинить ряд одного горизонта по аналогии с другим горизонтом. Поэтому целью дальнейших исследований является анализ длинных рядов наблюдений.

В заключение отметим, что при наличии большого массива первичного материала описанная методика позволяет сократить объем исходных данных, а также отделить фоновый режим подземных вод от частностей, т. е. позволяет в сущности проводить районирование режима.

\section{ЛИТЕРА Т У РА}

В ер те А. 1965. Основные черты гидрогеологического строения и формирования подземных вод Эстонского артезианского бассейна, Изв. АН ЭССР, Биол., № 4 $563-586$.

К ра м бейн У., К а у фмен М., М ак - К ем мон Р. 1973. Модели геологических процессов. М., с. $120-135$. 


\section{T. METSLANG}

\section{UHEST EESTI PÖHAVEE TASEME REZIIMI KLASSIFITSEERIMISE VIISIST}

Pōhjavee tasemete kōikumise graafikuid rühmitades saame iga veelademe režiimile vastava graafikute rühma. Mõned graafikud peegeldavad summaarselt mitme veelademe režiimi, kuid omaette rühma nad ei moodusta, vaid kuuluvad prevaleeriva režiimiga veelademe rühma. Rühmitamine pōhineb graafikute paariviisilisel võrdlusel. Mida suurem on nende omavaheline sarnasus, seda väiksem on valemiga (4) määratud sarnasuse mõōt.

\section{T. METSLANG}

\section{ON A MODE OF CLASSIFYING THE LEVEL REGIME OF ESTONIAN UNDERGROUND WATER}

When grouping the dendrographs conveying the fluctuation of the levels of underground water, we obtain a group of dendrographs typifying the regime of each water stratum. Some graphs reflect summarily the regime of several water strata, but they do not form a separate group, being representative of the prevalent regime, only. The grouping is based on a comparison of dendrographs by pairs. The greater the resemblance of the two dendrographs, the smaller is the measure of the resemblance determined by the formula (4). 